\title{
Complications of triple pregnancy following intracytoplasmic sperm injection: a case report
}

\author{
DC Nkemayim, ME Hammadeh, M Hippach, P Rosenbaum and W Schmidt \\ Department of Obstetrics and Gynaecology, University of Saarland, Homburg, Germany
}

\begin{abstract}
A case is presented of pregnancy and delivery of triplets following intracytoplasmic sperm injection (ICSI) therapy. Although the outcome was satisfactory, with the birth of normal children free from any malformation, most of the obstetric and particularly the neonatal complications that can be associated with this therapy are illustrated in this case. In addition, from point of view of medical costs, concerns are raised about the current policy of multiple embryo transfer which is directly responsible for the high rate of multiple gestations observed in the IVF/ICSI programme. The authors consequently recommend a policy of transferring not more than two embryos per treatment cycle. Twin Research (2000) 3, 76-79.
\end{abstract}

Keywords: pregnancy complications, ICSI, ovarian hyperstimulation syndrome, premature delivery

\section{Introduction}

The current decade has witnessed major developments in assisted reproduction technology. This has included particularly the advent of intracytoplasmic sperm injection (ICSI $)^{1}$ in which all the natural barriers to sperm-egg contact in the fertilisation process are bypassed, thus making it possible for couples with severe male factor infertility to realise their dream of biological parenthood. Although legitimate worries have been raised concerning the subsequent physical and mental well-being of children resulting from this therapy, ${ }^{2}$ evidence from current literature tends to dispel these concerns as studies have so far failed to indicate any particular risks compared with children conceived by natural conception. ${ }^{3-5}$ Nevertheless, assisted reproductive techniques are not free from undesirable effects, some of which may severely jeopardise the lives of both the mother and offspring. In addition, from the point of view of medical costs, there are legitimate concerns about the increasing rate of multiple gestations which is a direct consequence of multiple embryo transfer. We report on a case illustrating the economic impact of the medical complications of multiply gestation following ICSI therapy.

Correspondence: Dr Denis Chap Nkemayim, c/o Dr ME Hammadeh, Department of Obstetrics and Gynaecology, College of Medicine, University of Saarland, 66421 Homburg/Saar, Germany. Tel: $\quad+49(0) 6841168117$; Fax: $+49(0) 6841168061$; E-mail: frmham@med-rz.uni-sb.de

Received 6 December 1999; accepted 25 February 2000
Case history

A 29-year-old woman presented for inability to conceive despite cohabitation with her husband and adequate sexual exposure for a period of 5 years. On investigation she had signs of polycystic ovarian syndrome. Semen analysis of the husband reveal ed a sperm count of 0.5 million per $\mathrm{ml}$ of semen, $5 \%$ motility, and 4\% normal morphology (Kruger's strict criteria). On the basis of these very poor sperm parameters, intracytoplasmic sperm injection (ICSI) was considered the treatment of choice.

Ovarian hyperstimulation was carried out with purified FSH (Fertinorme HP, Serono GmbH, Überschließheim, Germany) at a daily dose of $150 \mathrm{IU}$ for 12 consecutive days, after prior down-regulation with GnRH analogue (Zoladex-Gyn-Depot, Zeneca, Plankstadt, Germany). Ovulation was later induced by $5000 \mathrm{IU}$ of HCG (Choragon, Ferring, Kiel, Germany) when the leading follicles were at least $18 \mathrm{~mm}$ and oestradiol (E2) levels of $200 \mathrm{pg} / \mathrm{ml}$ per follicle or more. After 36 hours 10 mature oocytes were retrieved under ultrasound control by transvaginal aspiration. ICSI was performed as previously described by Hammadeh et al. ${ }^{6}$ Eight out of the 10 oocytes injected showed signs of fertilisation 18 hours after injection. Three of the eight fertilised oocytes were randomly selected and cultured for further 24 hours, while the remaining five were cryopreserved in the pronucleus stage. Three embryos, all at 4-cell stage, were then transferred into the uterine cavity. Luteal phase support postembryo transfer was carried out by daily administration of progesterone vaginal capsules. This was maintained until 12 weeks of gestation. Meanwhile, by the 10th day after embryo transfer, the patient 
developed severe ovarian hyperstimulation syndrome, characterised by massive ascitis and pleural effusion which severely impaired lung function occasionally. The management was conservative with hospitalisation and supportive therapy, including i.v. hydration, infusion of albumin and electroIytes. During hospitalisation, paracentesis was carried out three times for severe dyspnoe. In all, a total of 12.5 litres of fluid was tapped from the patient's abdomen in order to ameliorate her respiration. At the 24th week of gestation cervical incompetence was diagnosed, for which late cerclage was carried out (Shirodker technique). In addition, throughout the pregnancy she suffered from repeated episodes of threatened abortion, characterised by vaginal bleeding, occasionally accompanied by uterine contractions. The pregnancy was successfully managed to a term of 32 weeks, after which she suffered another episode of preterm labour which did not improve with therapy. The membranes, however, remained intact. Dexamethasone was administered in an attempt to accelerate foetal lung maturation. After 5 days of unsuccessful attempts to arrest labour, delivery was finally conducted through an el ective Caeserian section (birth weights: 1910, 1190, 1590 grams; Apgar scores at the 1st, 5th, and 10th minutes and arterial blood $\mathrm{pH}$ were respectively $6 / 9 / 9,7 / 8 / 8,6 / 8 / 8$ and $7.32,7.30,7.19)$. The three babies all suffered from anaemia (haemoglobin levels ranging between 10.5 and $11.7 \mathrm{~g} / \mathrm{mL}$ ) with accompanying cyanosis. This was corrected by pack cell transfusion and phototherapy. They al so all suffered from severe respiratory distress syndrome requiring several days of intubation and intensive care. Two of the three developed staphylococcal sepsis in the course of hospitalisation, while one of them had hernia and hydrocele which were surgically repaired by the end of the second month of life. After a total of 60 days of hospitalisation, including 7 days of nursing in the intensive care unit, they were discharged in good health. No major or minor malformation was detected.

The total direct medical costs of the follow up of this pregnancy to delivery, including the 60-day hospitalisation of the infants, the costs of hospitalisation and treatment of immediate complications, was evaluated at US $\$ 150000$, being more than 50 times that of a normal singleton pregnancy in the same hospital!

\section{Discussion}

In most of the centres offering IVF/ICSI therapy the entire cost of treatment is the responsibility of the patients themselves. Even in the few countries where legislation on insurance cover for the treat- ment of infertility exists, there are usually restrictions about what procedures are covered. Such restrictions are usually applied to expensive procedures such as ICSI therapy. Consequently both the cost of evaluation and the treatment are passed directly to the individual couples, thus obliging both the physician and the patient to make infertility treatment decisions based on economic considerations rather than strictly the medical situation. This has recently become an issue of great concern, considering the high cost associated with the increasing rates of multiple gestation pregnancies which directly result from assisted reproduction procedures. ${ }^{7-9}$

The numerous complications associated with multiple gestations are well known. ${ }^{10-12}$ They consist mainly of premature delivery, low birth weights and numerous other related complications. Infant mortality associated with high-order multiple gestations has been reported to be 15 times that of singletons. ${ }^{8}$ This results almost entirely from prematurity. With an estimated annual cost of hospital services for multiple births arising from IVF treatment alone evaluated at $£ 4.3$ million in Britain, ${ }^{13}$ the cost of neonatal care of prematurely born infants may represent the largest single component of expenditure on multiple births. ${ }^{14}$ In one study the mean obstetric and neonatal charges for a singleton and twin deliveries were evaluated to be US\$9329 and 20318 , respectively, whereas those of triplets was as high as US\$153 335 dollars in the same institution. ${ }^{15}$ In other studies the charges for triplet deliveries have been evaluated at between US\$109765 ${ }^{11}$ and $340000,{ }^{16}$ compared with US\$9845 and 37947 for singleton and twin deliveries, respectively. ${ }^{11}$ It has al so been estimated that if all the multiple gestations resulting from assisted reproduction techniques were singl eton pregnancies, the predictive savings to the health care delivery system of a single hospital would account to US $\$ 3$ million per year! ${ }^{11}$ This has consequently led to much concern about the economic impact of multiple pregnancies on heal th care resources, ${ }^{17}$ thus underscoring the need to design cost-effective interventions aimed at reducing the rate of multiple gestations. ${ }^{11,12}$

The rational e hitherto for multiple embryo transfer in assisted reproduction procedures has been that the probability of achieving a pregnancy after the transfer of a single embryo is low. But this policy may not necessarily increase the pregnancy rate in ART programmes. Some studies have indicated that pregnancy and birth rates are not diminished by transferring two $0^{18}$ or even a single embryo. ${ }^{19,20}$ Although the embryo selection prior to transfer is considered unethical and unlawful in some countries, some authors have advocated this policy in order to preserve singleton pregnancies and to 
improve the pregnancy outcome..$^{21,22}$ If good pregnancy rates have been achieved with the transfer of single unselected embryos, ${ }^{19,20}$ then better results could be obtained if a single or two selected embryos are transferred in order to maintain good pregnancy rates while reducing the rate of multiple gestations to the minimum. Furthermore, although disputable ${ }^{23}$ it has been suggested that pregnancy rates could further be optimised by carrying out embryo transfer at the blastocyst stage which, from the physiological point of view, appears to be the most optimal stage of embryo transfer, ${ }^{24,25}$ In order to check the increasing rate of multiple gestations and its associated complications, a policy of reducing multiple gestations would be imperative. ${ }^{26}$

The cost analysis evaluated for the management of this case included only the direct medical expenditure of hospitalisation, costs of immediate complications, including hospitalisation for OHSS, drugs, physicians fees, laboratory tests, and radiological procedures for the mother as well as the costs incurred by the infants. The total cost of US\$150000 is not within the reach of the public. Yet it did not include non-medical costs, indirect morbidity and mortality costs, and intangible costs ${ }^{27}$ which are al so considered an integral part of the cost-effectiveness anal ysis for medical care. ${ }^{28,29}$ It is generally accepted that the major factor in the health care costs associated with IVF/ICSI therapy is the cost of caring for infants born prematurely as a result of multiple gestation. ${ }^{14}$ Therefore, reducing multiple gestations is of utmost importance in efforts to improve the cost-effectiveness in IVF/ICSI programmes.

Legislation in some countries permits the transfer of as many as six embryos. Under German legislation, in its embryo protection act (1990), not more than three embryos may be transferred at one time. Even so, the experience of the authors is that the transfer of three embryos exposes both the woman and the expected children to very serious complications, in addition to being very unfavourable for the economics of the health care system at large. Apart from the well documented high rate of maternal and neonatal morbidity and mortality resulting from high-order multiple gestations, ${ }^{9} .{ }^{10,30}$ the costs resulting from the care of these infants are very high. Therefore, the reduction of high-order multiple gestations in favour of duplex gestations or singleton pregnancies would not only be most desirable but al so most recommendable.

\section{References}

1 Palermo G, Joris H, Devroey P, Van-Steirteghem AC. Pregnancies after intracytoplasmic sperm injection of single spermatozoon into an oocyte. Lancet 1992; 340: 8-17.
2 Johnson MD. Genetic risks of intracytoplasmic sperm injection in the treatment of male infertility: recommendations for genetic counselling and screening. Fertil Steril 1998; 70: 570-574.

3 Nyboe AA, Westergaard HB, Jhansen AMT, Erb K. National Danish IVF registry 1994 and 1995. A controlled study of births, malformations and cytogenetic findings. Hum Reprod 1999; 14: 9-10.

4 Sutcliffe AG, Taylor B, Li J, Thornton S, Grudzinskas JG, Lieberman BA. United Kingdom study of children born after intracytoplasmic injection. Hum Reprod 1999; 14: 10.

5 Singh L, Senn A, De Grandi P, Germond P. Follow-up of 100 children, aged 1 and 2 years, born after intracytoplasmic sperm injection. Hum Reprod 1999; 14: 58.

6 Hammadeh ME, AI-Hasani S, Sti eber M, Rosenbaum P, Küpker $D$, Diedrich K, Schmidt W. The effect of chromatin condensation (Aniline Blue staining) and morphology (strict criteria) of human spermatozoa on fertilisation, cleavage and pregnancy rates in an intracytoplasmic sperm injection programme. Hum Reprod 1996; 11: 2468-2471.

7 Rein MS, Barbieri RL, Greene MF. The causes of high-order multiple gestation. Int J Fertil 1990; 35: 154-6.

8 Kiely $\mathbf{L}$, Kleinman $\mathbf{J}$, Kiely $\mathbf{M}$. Triplets and high-order multiple births: time trends and infant mortality. Am J Dis Child 1992; 146: 862-8.

9 Levene MI, Wild J, Steer P. Higher multiple births and the modern management of infertility of the couple in Britain. $\mathrm{Br}$ J Obstet Gynaecol 1992; 99: 607-13.

10 Lipitz S, Frenkel Y, Watts C, Ben-Rafael Z, Barkai G, Reichman B. High-order multifetal gestation: management and outcome. Obstet Gynecol 1990; 76: 215-8.

11 Callahan TL, Hall JE, Ettner SL, Christiansen CL, Greene MR, Crowley WF $\mathbf{J}$. The economic impact of multiple-gestation pregnancies and the contribution of assisted reproduction techniques to their incidence. N Engl J Med 1994; 331: 244-9.

12 Ettner SL, Christiansen CL, Callahan TL, Hall JE. 'How low birth weight and gestational age contribute to increased in-patient cost for multiple birth' - Inquiry. 1997-1998 Winter 1997; 34: 325-39.

13 Lieberman B. Complications of multiple pregnancies. Hum Reprod 1999; 14: 52

14 Bradley J, Van Voorhis MD, Dale WS, Brian D, Allen BGS, Craig HS. Cost-effective treatment of the infertile couple. Fertil Steril 1998; 70: 995-1005.

15 Hidlebaugh DA, Thompson IE, Berger MJ. Cost of artificial reproduction technologies for a heal th maintenance organisation. JReprod Med 1997; 42: 570-574.

16 Goldfarb M, Austin C, Lisbona H, Peskin B, Clapp M. Costeffectiveness of in vitro fertilization. Obstet Gynecol 1996; 87: 18-21.

17 Chelmow D, Penzias AS, Kaufman G, Cetrulo C. Costs of triplet pregnancy. Am J Obstet Gynecol 1995; 172: 677-682.

18 Templeton A, Morris $\mathbf{K}$. Reducing the risk of multiple births by transfer of two embryos after in vitro fertilization. $\mathrm{N}$ Engl $\mathrm{J}$ Med 1998; 339: 573-577.

19 Raziel A, Friedler S, Schachter M, Strassburger D, Komarovsky D, Bern O, Kaster E, Ron-El R. The efficacy of a single available transferred embryo after ICSI. Hum Reprod 1999; 14: 5-6.

20 Vilska S, Tiitinen A, Hyden-Granskog C, Howatta O. Elective transfer of one embryo results in an acceptable pregnancy rate and eliminates the risk of multiple birth. Hum Reprod 1999; 14: 2392-2395.

21 Wapner RJ, Davis GH, Johnson A, Weinblatt VJ, Fischer RL, Jackson LJ, Chervenak FA, McCullough LB. Selective reduction of multifetal pregnancies. Lancet 1990; 335: 90-93.

22 Herlicoviez M, Denis I, Barjot P, Lindet Y, Delautre V, Refahi N, Marie E. Multifetal pregnancy reduction. Hum Reprod 1999; 14: 206. 
23 Ashkenazi J, Yoeli R, Bar-Hava I, Bardin R, Orvieto R, Feldberg D, Voliovich I, Shelef M, Schwartz A, Ben-Rafael Z. Effect of double transfer (early embryos and blastocysts) on pregnancy and implantation rates. Hum Reprod 1999; 14: 81-82.

24 Alvarez C, Ten J, Llá J, Garcia-Enguidanos A, Bernabeu R. Development of excess embryos to the blastocyst stage predicts pregnancy rates after in-vitro fertilization and intracytoplasmic sperm injection. Hum Reprod 1999; 14: 197.

25 Bongso A. Why blastocyst culture? In Handbook of Blastocyst Culture: Copyright 1999 - Department of Obstetrics and Gynaecology: National University of Singapore: National University Hospital, Lower Kent Ridge Road, Singapore 119074. Sydney Press Indusprint (S) Pte Ltd, 1999, p 15.

26 Gerris J, De Neubourg D, Van Royen E, Mangelschots K, Val enburg M, Van de Meerssche M, Ryckaert G, Eestermans W, Goiris J, Loostens M. Prevention of twin pregnancy after in-vitro fertilisation/intracytoplasmic sperm injection based on strict embryo criteria: a prospective randomised clinical trial. Hum Reprod 1999; 14: 8.
27 Eisenberg $\mathbf{M}$. Clinical economics: a guide to the economic analysis of clinical practices. J Am Med Assoc 1989; 262: 2879-2886.

28 Drummond M, Stoddart G, Labelle R, Cushman R. Health economics: an introduction for clinicians. Ann Intern Med 1987; 107: 88-92.

29 Detsky AS, Naglie IG. A clinicians guide to cost-effectiveness analysis. Ann Intern Med 1990; 113: 147-154.

30 Lipitz S, Reichman B, Paret G, Modan M, Shalev J, Serr DM, Mashiach S, Frenkel Y. The improving outcome of triplet pregnancies. Am J Obstet Gynecol 1989; 161: 1279-1284. 